\title{
Airway reactivity to mannitol is similarly increased in chronic cigarette and water pipe smokers
}

This article was published in the following Dove Press journal: International Journal of COPD

\section{Andreas Scherr Jerome Schmidlin \\ Silvio Albisser \\ Michael Tamm \\ Daiana Stolz}

Clinic for Pneumology and Respiratory Cell Research, University Hospital of Basel, Basel, Switzerland
Correspondence: Daiana Stolz Clinic for Pneumology and Respiratory Cell Research, University Hospital of Basel, Petersgraben 4, CH-403I Basel, Switzerland

Tel $+4|6| 2655184$

Fax +4I 6I 2654587

Email daiana.stolz@usb.ch
Background: In contrast to cigarette smoking, the association between water pipe smoking and airway hyperresponsiveness remains widely unexplored.

Methods: A bronchoprovocation challenge with mannitol was performed in young adults recruited at the University of Basel, Switzerland. Subjects were categorized as acute water pipe smokers (single episode of water pipe smoking, no or $<0.5$ pack-years cigarette smoking); chronic water pipe smokers (weekly for $\geq 4$ weeks, no or $<0.5$ pack-years cigarette smoking); cigarette smokers (no water pipe smokers); and never-smokers (no cigarette or water pipe smokers). Primary outcomes were airway reactivity as measured by the response-to-dose ratio (RDR) and airway responsiveness measured by the provocation dose to cause a $15 \%$ fall in forced expiratory volume in $1 \mathrm{~s}\left(\mathrm{FEV}_{1} ; \mathrm{PD}_{15}\right)$.

Results: Seventy-four subjects with a mean age of $22.5 \pm 2.5$ years and $\mathrm{FEV}_{1} \%$ predicted $90.1 \% \pm 8.6 \%$ were included. Subgroups were matched in terms of age, gender, and spirometry results. RDR in chronic water pipe smokers and cigarette smokers was similar $(0.013 \% / \mathrm{mg}$ [0.010-0.015] vs $0.023 \% / \mathrm{mg}[0.011-0.051]$, respectively; $p=0.12$ ) but significantly higher than in never-smokers $(0.007 \% / \mathrm{mg}[0.005-0.010], p<0.01)$. Neither a history of asthma $(p=0.88)$ nor a positive skin prick test $(p=0.69)$ was associated with increased airway reactivity to the mannitol challenge test. $\mathrm{PD}_{15}$ differed significantly between cigarette smokers and never-smokers (155 mg [115-395] vs 315 mg [155-475], respectively; $p=0.04$ ).

Conclusion: Weekly water pipe smoking may increase airway reactivity to a similar extent as cigarette smoking.

Keywords: mannitol challenge, airway reactivity, water pipe smoking

\section{Introduction}

There is a steady increase in the prevalence of water pipe smoking in the Western world. ${ }^{1}$ Of the young adults aged $16-30$ years, $\sim 80 \%$ report having smoked water pipe, $30 \%$ currently smoke, and $4 \%$ regularly smoke water pipe. ${ }^{2}$ The increase in prevalence of water pipe smoking could be attributed to the following: 1) water pipes are socially more acceptable than cigarettes with bars specifically catering for the smoking of water pipes; 2) it is cheaper to smoke a water pipe than cigarettes since they are often shared at home or in dedicated bars; 3 ) consumers tend to assume that smoking water pipe is less harmful than smoking cigarettes because the smoke passes through a reservoir of water which is thought to filter hazardous chemicals; 4) furthermore, the tobacco control policies in the US and many other Western countries currently do not adequately address water pipe smoking. ${ }^{2-4}$

It is widely accepted that the inhalation of tobacco smoke is the single most important risk factor for the development of chronic airway disease. There is accumulating evidence implying that water pipe smokers experience similar health risks as cigarette 
smokers. ${ }^{1,4,5}$ However, the interpretation of the available data is hampered by the fact that most water pipe smokers report concomitant cigarette smoking, thus confounding the individual risk associated with each exposure. Cigarette smoke has the capacity to damage the airways in a number of ways, including direct toxicity to the epithelium, increased oxidative damage, induction of inflammatory cells, particularly neutrophils, and increased epithelial permeability. ${ }^{5,6}$ Subsequently, airway inflammation leads to chronic respiratory symptoms, ie, chronic cough and sputum production, along with irreversible airflow limitation in susceptible individuals. ${ }^{7-9}$

In non-asthmatic patients, cigarette smoking has been shown to induce airway hyperresponsiveness (AHR). ${ }^{8,10}$ The extent and reversibility of AHR following smoking cessation is dependent on the stimulus. ${ }^{11,12}$ Mannitol is an indirect stimulant which can be used to measure AHR. ${ }^{13}$ Asymptomatic cigarette smokers with normal lung function show a high prevalence of AHR compared to never-smokers when stimulated with mannitol, and this effect is reversed following smoking cessation. ${ }^{12}$ In contrast to cigarette smoking, the relationship between other forms of tobacco inhalation, such as water pipe smoking, and the development of AHR remains widely unexplored. The present study aimed to determine whether airway reactivity and responsiveness to mannitol differs between 1) acute water pipe smokers (single episode of water pipe smoking, no cigarette smoking); 2) chronic water pipe smokers (weekly for $\geq 4$ weeks; no cigarette smoking); 3 ) cigarette smokers (no water pipe smoking); and 4) neversmokers (no water pipe and no cigarette smoking). A 15\% fall in forced expiratory volume in $1 \mathrm{~s}\left(\mathrm{FEV}_{1}\right)$ in response to the mannitol challenge is considered a positive test, and the response-to-dose ratio (RDR) represents a measure of the reactivity to mannitol. ${ }^{12,14}$

\section{Ethics statement}

The study was submitted to the local Institutional Review Board of the Canton Basel, Switzerland (Ethics Committee of Basel, EKBB/EKNZ 116/9) who approved all ethical aspects related to the study. All participants provided written informed consent for the scientific analysis of their data.

\section{Methods}

\section{Setting and study population}

The present study was designed as a prospective, single-center, observational trial and was conducted at the University Hospital Basel, Switzerland. University students were recruited by personal contact or advertisement on blackboards at the university campus. Included subjects received an incentive in the form of a cinema voucher. The inclusion criteria were age between 18 and 30 years and current student status. Exclusion criteria were as follows: current clinical diagnosis of asthma or signs and symptoms suggestive of asthma; a history of active upper or lower respiratory tract infection severe enough to require medical consultation in the past 2 years; any known acute or chronic pulmonary disorder (including, but not limited to, cystic fibrosis, tuberculosis, bronchiectasis, and emphysema); breast feeding or pregnancy; known intolerance to mannitol or bronchodilators (salbutamol); consumption of any other tobacco products (including marijuana, cigars, pipes, e-cigarettes; all possible tobacco products were excluded which strongly restricted the number of volunteers that could be included); and intake in the past 6 months of any medication or drugs that would directly or indirectly influence the mannitol challenge test (eg, bronchodilators, corticosteroids, theophylline, anti-histamines, and leukotriene antagonists). Subjects were categorized into four groups according to the reported smoking habits - acute water pipe smokers were defined by a self-reported single episode of water pipe smoking within the last $48 \mathrm{~h}$, after minimal abstinence of 14 days and with no other smoke exposure in the last 6 months; chronic water pipe smokers were defined by a $\geq$ once weekly water pipe smoking session for at least the last 4 weeks and no other smoke exposure within the last 6 months. Active cigarette smoking was defined by a consumption of at least 10-30 cigarettes per day within the last 3 months. Patients categorized as acute and chronic water pipe smokers were either never-smokers or reported only a minimal cigarette smoke exposure $(<0.5$ pack-years [PY]). The study was conducted in accordance with the Good Clinical Practice guidelines recommended by the International Conference on Harmonisation of Technical Requirements and the Declaration of Helsinki. ${ }^{15,16}$ The study was submitted to the local Institutional Review Board (EKBB/ EKNZ 116/9) which approved all ethical aspects related to the study. All participants provided written informed consent allowing the scientific analysis of their data.

\section{Assessments}

At enrollment, demographic data were collected, followed by a thorough assessment of health status, including medical history and relevant comorbidities. Data on smoking were collected with standardized questions about current and previous smoking habits. Active cigarette smokers were asked for the number of PY and the number of cigarettes smoked daily within the last 3 months. All students underwent lung function testing. Therefore, $\mathrm{FEV}_{1}$, forced vital capacity 
(FVC), and $\mathrm{FEV}_{1} / \mathrm{FVC}$ were measured using a spirometer (Spirovit SP-10; Schiller, Baar, Switzerland) according to the American Thoracic Society guidelines. ${ }^{17}$ Exhaled carbon monoxide (CO) was measured with a Micro Smokerlyzer device (Bedfont Scientific, Maidstone, UK). All participants underwent a skin prick test and mannitol challenge. Skin prick tests were performed using Phazet lances (Pharmacia Diagnostic AB, Uppsala, Sweden) on the volar side of the forearm. A standard panel (Trimedal AG, Dietlikon, Switzerland) was used, comprising six common aeroallergens in this region: the mold Alternaria tenuis, the mold Cladosporium hormodendrum, mixed grass, cat dander, dog dander, and the house dust mite Dermatophagoides pteronyssinus. Histamine $10 \mathrm{mg} / \mathrm{mL}$ was used as a positive control and a saline/glycerol solution as a negative control. Skin test reactions (weal size) were read along the long axis and perpendicular to the long axis after $15 \mathrm{~min}$. A mean weal size of $\geq 3 \mathrm{~mm}$ was regarded as a positive response. ${ }^{18}$ Subjects were considered atopic if they had a positive reaction to one or more of the eight allergens. The mannitol challenge was performed by administering the spray-dry mannitol powder released from a gelatin capsule form (AridolTM; Pharmaxis Ltd, Sydney, Australia) and inhaled through an RS01 device, as described by Anderson et al. ${ }^{13}$ Based on the results by Brannan et al, mean RDR in healthy never-smokers was considered to be $\sim 0.0029 \%$ fall per mg applied mannitol ( $95 \%$ confidence interval [CI] 0.002; 0.004) ${ }^{14} \mathrm{RDR}$ is defined as the maximum percentage fall in $\mathrm{FEV}_{1}$ /cumulative dose of mannitol. All subjects were dissuaded from any kind of smoking for $6 \mathrm{~h}$ before the test.

\section{Power calculation and statistical data analysis}

Sample size calculation was performed based on the difference in the prevalence of AHR between water pipe smokers and never-smokers. Assuming that AHR to mannitol would be present in $~ 30 \%$ of water pipe smokers and $5 \%$ of nonsmokers, 27 subjects would be needed in each arm (total $\mathrm{n}=108$ ) to achieve a $5 \%$ significance with a power of $80 \%$. Since there are no comparable data available, our assumption about the prevalence of AHR in water pipe smokers was made based on the results of a former study investigating the prevalence of AHR in cigarette smokers. ${ }^{12}$ Differences between study subgroups in dichotomous and continuously distributed variables were analyzed by using the chi-square test and the nonparametric Mann-Whitney $U$-test or Kruskal-Wallis test, as appropriate. To compare differences in RDR between the study groups, ANOVA with subsequent comparisons was performed using logarithmically transformed data.
Provocation dose to cause a $15 \%$ fall in $\mathrm{FEV}_{1}\left(\mathrm{PD}_{15}\right)$ was logarithmically transformed using a base- 2 logarithm. All statistical analyses were performed with the Statistical Package for Social Sciences (SPSS Inc, version 22 for Windows). A $p$-value of $<0.05$ was considered significant.

\section{Results}

\section{Baseline data and study population}

Baseline characteristics for each of the four subgroups are illustrated in Table 1. In total, 230 subjects were initially screened for eligibility. A total of 74 students fulfilled the inclusion criteria (Figure 1). On average, the study population consisted of young university students in their early $20 \mathrm{~s}$ (mean 22.5 years, $\mathrm{SD} \pm 2.5$ ) with nearly equal proportions of males (51\%) and females (49\%). The prevalence of comorbidities was low with two cases of iron deficiency anemia and two cases of lactose intolerance. Concomitant medication consisted of oral contraceptives and dietary supplements. Participants denied any current respiratory symptoms at inclusion. A positive reaction to at least one common aeroallergen was observed in about half of the participants (51\%). One subject reported a history of mild exercise-induced asthma in childhood, but had a negative bronchoprovocation with mannitol ( $\mathrm{PD}_{15}$ was not reached). Spirometry parameters were within the normal range. The four subgroups were matched in terms of age, gender, and spirometry results. Cigarette smokers reported a median of 20 cigarettes per day (interquartile range [IQR] 15-30) with a mean smoking history of 5.9 \pm 3.2 PY. Exhaled CO was significantly higher in chronic cigarette smokers compared to acute and chronic water pipe smokers $(p<0.01)$. As defined per protocol, both acute and chronic water pipe smokers denied any additional consumption of cigarettes or other tobacco products.

\section{Mannitol challenge test results}

The mannitol bronchoprovocation test results are displayed in Table 2. Overall, $\mathrm{PD}_{15}$ in response to the mannitol challenge test was observed in 7 of 74 participants $(9.5 \%)$. Of these, five participants were cigarette smokers $(6.5 \pm 2.3 \mathrm{PY})$ with a median provocation dose of $155 \mathrm{mg}(155-395 \mathrm{mg})$ and two were never-smokers with a median provocation dose of $315 \mathrm{mg}(155-475 \mathrm{mg})$. All other participants did not reach a $\mathrm{PD}_{15}$ after an application of a cumulative dose of $635 \mathrm{mg}$ mannitol, ie, these participants had a negative mannitol test.

There was a significant difference in airway reactivity to mannitol as measured by the RDR across the four groups $(p=0.03)$. Median RDR was highest in cigarette smokers $(0.023 \% / \mathrm{mg}$ [0.011-0.051]) followed by chronic water 
Table I Demographic and clinical baseline data according to smoking status

\begin{tabular}{|c|c|c|c|c|c|c|}
\hline Variables & $\begin{array}{l}\text { All } \\
(n=74)\end{array}$ & $\begin{array}{l}\text { Water pipe } \\
\text { (acute) } \\
(n=15)\end{array}$ & $\begin{array}{l}\text { Water pipe } \\
\text { (chronic) } \\
(n=9)\end{array}$ & $\begin{array}{l}\text { Cigarette } \\
\text { smokers } \\
(n=18)\end{array}$ & $\begin{array}{l}\text { Never- } \\
\text { smokers } \\
(n=32)\end{array}$ & $p$-value \\
\hline \multicolumn{7}{|l|}{ Gender } \\
\hline Female, n (\%) & $36(49)$ & $8(53)$ & $4(44)$ & $8(44)$ & $16(50)$ & 0.34 \\
\hline Age, years & $22.5( \pm 2.5)$ & $21.8( \pm 1.5)$ & $22.7( \pm 4.3)$ & $23.0( \pm 2.7)$ & $22.5( \pm 2.5)$ & 0.52 \\
\hline \multicolumn{7}{|l|}{ Smoking } \\
\hline Pack-years & $1.7(0-3)$ & 0 & & $5.9(4-6.5)$ & 0 & - \\
\hline Cigarettes/day* (IQR) & $20(15-20)$ & 0 & 0 & $20(15-20)$ & 0 & - \\
\hline $\mathrm{CO}, \mathrm{ppb}$ & $5.4( \pm 7.3)$ & $2.13( \pm 1.8)$ & $4.9( \pm 3.3)$ & $15.3( \pm 8.2)$ & $1.3( \pm 2.3)$ & $<0.01$ \\
\hline \multicolumn{7}{|l|}{ Atopic status } \\
\hline Allergies, n (\%) & $19(26)$ & $5(33)$ & $3(33)$ & $5(26)$ & $6(19)$ & 0.61 \\
\hline Prick test (positive) & $38(5 \mathrm{I})$ & $6(40)$ & $5(55)$ & $6(31)$ & $13(4 \mid)$ & $<0.01$ \\
\hline History of asthma, $n(\%)$ & $4(5)$ & I (7) & $0(0)$ & $0(0)$ & $3(9)$ & \\
\hline Comorbidities, n (\%) & $4(5)$ & I (7) & $0(0)$ & $0(0)$ & $3(9)$ & - \\
\hline Medication, n (\%) & $23(3 \mathrm{I})$ & $7(46)$ & $2(22)$ & $7(37)$ & $7(22)$ & - \\
\hline \multicolumn{7}{|l|}{ Spirometric indices } \\
\hline $\mathrm{FEV}_{1}(\mathrm{~L})$ & $3.8( \pm 0.7)$ & $3.7( \pm 0.8)$ & $3.9( \pm 0.8)$ & $3.8( \pm 0.6)$ & $3.7( \pm 0.7)$ & 0.48 \\
\hline $\mathrm{FEV}_{1}$ (\% predicted) & $90.1( \pm 8.6)$ & $91.4( \pm 8.6)$ & $93.5( \pm \mid 3.2)$ & $89.0( \pm 3.8)$ & $88.8( \pm 8.6)$ & 0.65 \\
\hline FVC \% (L) & $4.6( \pm 0.8)$ & $4.4( \pm 0.9)$ & $4.8( \pm I .0)$ & $4.5( \pm 0.6)$ & $4.6( \pm 0.7)$ & 0.54 \\
\hline FVC (\% predicted) & $92.1( \pm 8.9)$ & $91.9( \pm 7.3)$ & $98.3( \pm 10.6)$ & $91.2( \pm 7.0)$ & $90.8( \pm 10.1)$ & 0.08 \\
\hline $\mathrm{FEV}_{1} / \mathrm{FVC} *( \pm \mathrm{IQR})$ & $0.83( \pm 0.1)$ & $0.86( \pm 0.1)$ & $0.81( \pm 0.1)$ & $0.84( \pm 0.6)$ & $0.81( \pm 0.1)$ & 0.49 \\
\hline
\end{tabular}

Notes: Data are presented as $n(\%)$, mean $\pm \mathrm{SD}$, or *median (IQR). $p<0.05$ is significant (two-sided unpaired $t$-test for continuous variables, chi-square for discontinuous variables). The groups were defined as follows: I) acute water pipe smokers (single episode of water pipe smoking, no cigarette smoking); 2 ) chronic water pipe smokers (weekly for $\geq 4$ weeks; no cigarette smoking); 3) cigarette smokers (no water pipe smoking); and 4) never-smokers (no water pipe and no cigarette smoking).

Abbreviations: $\mathrm{CO}$, carbon monoxide; $\mathrm{FEV}_{1}$, forced expiratory volume in I s; FVC, forced vital capacity; IQR, interquartile range; PY, pack-years.

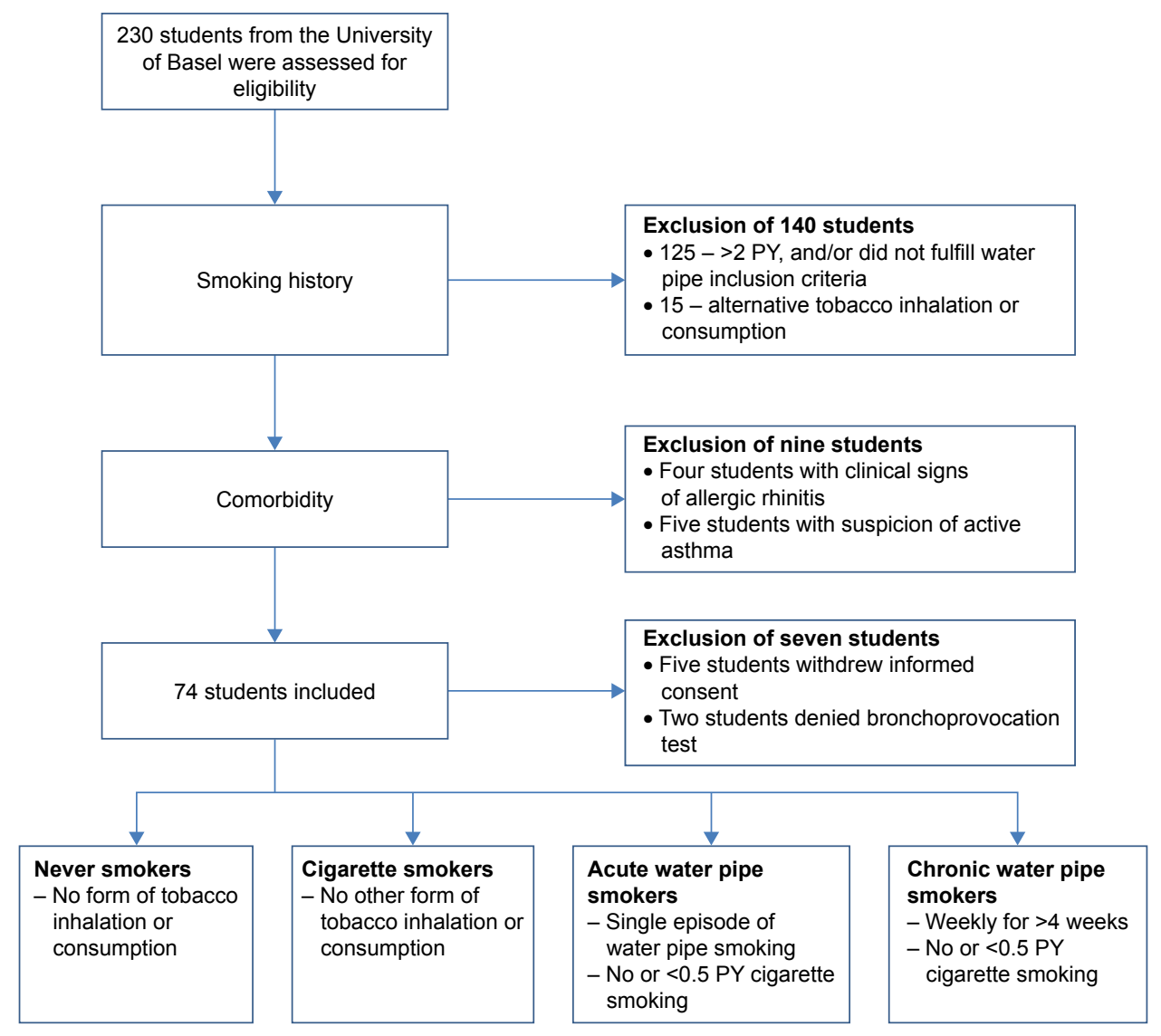

Figure I Flowchart depicting the study design. Abbreviation: PY, pack-years. 
Table 2 Mannitol challenge results in 74 subjects according to smoking status

\begin{tabular}{|c|c|c|c|c|c|c|}
\hline $\begin{array}{l}\text { Mannitol } \\
\text { challenge }\end{array}$ & $\begin{array}{l}\text { All } \\
(n=74)\end{array}$ & $\begin{array}{l}\text { Water pipe } \\
\text { (acute) } \\
(n=I 5)\end{array}$ & $\begin{array}{l}\text { Water pipe } \\
\text { (chronic) } \\
(n=9)\end{array}$ & $\begin{array}{l}\text { Cigarette } \\
\text { smokers } \\
(n=18) \\
\end{array}$ & $\begin{array}{l}\text { Never-smokers } \\
(n=32)\end{array}$ & $p$-value \\
\hline Positive, n (\%) & $7(10)$ & $0(0)$ & $0(0)$ & $5(27)$ & $2(7)$ & - \\
\hline Negative, n (\%) & $67(90)$ & $15(100)$ & $9(100)$ & $13(73)$ & $30(93)$ & - \\
\hline $\mathrm{PD}_{15}(\mathrm{mg}), *(\mathrm{IQR})$ & - & - & - & $155(115-395)$ & $315(155-475)$ & 0.04 \\
\hline RDR (\%/mg)* (IQR) & $0.011(0.022-0.050)$ & $0.010(0.006-0.015)$ & $0.013(0.010-0.015)$ & $0.023(0.0 \mathrm{II}-0.05 \mathrm{I})$ & $0.007(0.004-0.010)$ & 0.03 \\
\hline Fall in \% $\mathrm{FEV}_{1}^{*}(\mathrm{IQR})$ & $-4.67(-7.31$ to -2.29$)$ & $-4.83(-6.88$ to -3.97$)$ & $-6.04(-8.11$ to -4.04$)$ & $-7.25(-15.75$ to -3.48$)$ & $-3.05(-5.72$ to -1.43$)$ & $<0.01$ \\
\hline
\end{tabular}

Notes: The groups were defined as follows: I) acute water pipe smokers (single episode of water pipe smoking, no cigarette smoking); 2) chronic water pipe smokers (weekly for $\geq 4$ weeks; no cigarette smoking); 3) cigarette smokers (no water pipe smoking); and 4) never-smokers (no water pipe and no cigarette smoking). Data are presented as $\mathrm{n}$ (\%) or *median (IQR). Response-to-dose ratio (fall in FEV, divided by cumulative mannitol dose given to cause this fall).

Abbreviations: $\mathrm{FEV}_{1}$, forced expiratory volume in I s; IQR, interquartile range; $\mathrm{PD}_{15}$, provocation dose to cause a $15 \%$ fall in $\mathrm{FEV}$; $R \mathrm{RDR}$, response-to-dose ratio.

pipe smokers $(0.013 \% / \mathrm{mg}[0.010-0.015])$, acute water pipe smokers $(0.010 \% / \mathrm{mg}[0.006-0.015])$, and never-smokers $(0.007 \% / \mathrm{mg}[0.004-0.010])$. RDR was significantly different between cigarette smokers and both acute water pipe smokers $(p=0.02)$ and never-smokers $(p<0.01)$. However, there was no significant difference in RDR between cigarette smokers and chronic water pipe smokers $(p=0.12)$. Neither a history of asthma $(p=0.88)$ nor a positive skin prick test $(p=0.69)$ was associated with RDR.

\section{Discussion}

To the best of our knowledge, this is the first study investigating the effect of water pipe smoking on airway reactivity to a bronchoprovocation stimulus. In a cohort of healthy young adults with preserved lung function, water pipe smoking of $\sim 2$ years results in a similar dose-response curve to mannitol, ie, increased airway reactivity, as cigarette smoking of on average 5.9 PY.

The smoke inhaled through a water pipe is considered to contain larger amounts of noxious agents than cigarette smoke, such as hydrocarbons, carbon monoxide, and polycyclic aromatic aldehydes. ${ }^{19,20}$ Furthermore, water pipe smoking has been associated with a higher amount of inhaled ultrafine particles and toxic carbon dioxide per single breath compared to cigarettes. ${ }^{19,21} \mathrm{~A}$ single water pipe session is associated with a 50-100 times greater smoke volume inhaled than from a single cigarette. However, smoking habits from water pipe and cigarette smokers differ significantly. ${ }^{22-24}$ The majority of water pipe smokers smoke less frequently, typically one to two sessions per week or month, compared to the average cigarette smokers with $10-20$ cigarettes per day. There is mounting evidence that chronic water pipe smoke can negatively affect lung health as expressed by chronic respiratory symptoms (cough and sputum production) and impairment of lung function. ${ }^{24-26}$ Conversely, subacute, nose-only exposure to water pipe smoke in mice caused lung inflammation and oxidative stress, but did not affect pulmonary function. ${ }^{27}$ Strikingly, recent data suggest that young, light-use water pipe smokers have a lower diffusion capacity, abnormal epithelial lining, fluid metabolome profile, increased proportions of small airway epithelial secretory and intermediate cells, and reduced proportions of small airway epithelial ciliated cells as compared to non-smokers. ${ }^{28}$ Furthermore, markedly abnormal small airway epithelial and alveolar macrophage transcriptomes as well as elevated levels of apoptotic endothelial cell microparticles were reported, highlighting that the major bronchial changes caused by water pipe exposure might differ from those associated with cigarette smoking. ${ }^{28}$

In the present study, we could demonstrate that young adults with a modest amount of water pipe smoke exposure (at least once weekly) showed a significant increase of airway reactivity (RDR) similar to cigarette smokers. In other words, despite its dissimilarities, regular inhalation of water pipe smoke seems to have the same capability to induce nonasthmatic airway inflammation as cigarette smoke. Considering the inadequate legislature governing water pipe smoking, our findings strongly suggest that stricter laws should be implemented regarding water pipe smoking.

Water pipe smoking appears to be strongly associated with the concomitant use of other tobacco products such as cigarette smoking and also cannabis consumption. ${ }^{2,29-31}$ Therefore the true impact of water pipe smoke on airway inflammation remains difficult to be estimated. In the present study, we made sure to recruit only water pipe users with no relevant concomitant cigarette smoking. However, the identification of water pipe smokers who never smoked cigarettes and were thus eligible for the study was challenging and resulted in a smaller sample size than originally planned. Although we observed an increase in airway reactivity of chronic water pipe smokers, no effect on airway responsiveness $\left(\mathrm{PD}_{15}\right)$ was evident. There may be a few reasons for this occurrence, 
namely, that the population investigated consisted of young adults with no significant ancillary use of cigarettes and only a modest consumption of water pipe smoke. A positive mannitol test requires the presence of inflammatory cells, particularly mast cells and eosinophils. In mice, it was found that noseonly water pipe smoking 5 days a week for 1 month results in increased neutrophil and lymphocyte concentrations. ${ }^{32}$ The damage caused to the lung tissue by water pipe smoking may have a different mechanistic pathway so that the constituents needed for a positive mannitol test are either absent or require more time to develop. Nevertheless, it is tempting to hypothesize that long-term water pipe smoking might lead to more prominent changes in airway responsiveness. Importantly, our investigation was designed as an observational study providing a small sample size and no long-term follow-up. Thus, our results should be interpreted with caution, and larger, longitudinal studies will be required to definitely characterize changes in airway reactivity and the clinical consequences of water pipe smoking more precisely.

In conclusion, beyond the existing epidemiological evidence, the results of the present study suggest that modest water pipe exposure results in an increase in airway reactivity similar to cigarette smoking, which may reflect a preliminary state of airway disease.

\section{Availability of data and material}

All data generated and/or analyzed during the current study are included in this published article.

\section{Acknowledgments}

We thank Ms Anja Meyer for her invaluable contribution as study nurse.

Daiana Stolz was supported by grants from the Swiss National Foundation (PP00P3_128412/1). Additional funding was granted by the Clinic of Pulmonary Medicine, University Hospital Basel, Switzerland. The sponsor of this investigator-initiated project had no involvement in design and conduct of the study, collection, management, analysis, and interpretation of the data, nor in the preparation, review, and approval of the manuscript or decision to submit the manuscript.

The abstract of this paper was presented at the Joint Annual Meeting of the Swiss Society of Cardiology, the Swiss Society of Cardiac and Thoracic Vascular Surgery, and the Swiss Society of Pneumology, June 15-17, 2016, in Lausanne, Switzerland, and at the ERS International Congress London 2016 as a poster presentation, with interim findings. The posters' abstract was published in Abstracts, Respiration.
2016;91:414-468 and Cardiovascular Medicine. 2016; 19(5). It was also presented at the 21st Annual Congress, Amsterdam, the Netherlands, September 24-28, 2011, and the abstract was published in the European Respiratory Journal. 2011;38(Suppl 55).

\section{Author contributions}

MT, DS, JS, and SA participated in the conception and design and AS, JS, MT, and DS were involved in the final analysis and data interpretation. All authors contributed toward data analysis, drafting and critically revising the paper, gave final approval of the version to be published, and agree to be accountable for all aspects of the work.

\section{Disclosure}

The authors report no conflicts of interest in this work.

\section{References}

1. Jackson D, Aveyard P. Waterpipe smoking in students: prevalence, risk factors, symptoms of addiction, and smoke intake. Evidence from one British university. BMC Public Health. 2008;8:174.

2. Albisser S, Schmidlin J, Schindler C, Tamm M, Stolz D. Water pipe smoking and its association with cigarette and cannabis use in young adults in Switzerland. Respiration. 2013;86(3):210-215.

3. Colditz JB, Ton JN, James AE, Primack BA. Toward effective water pipe tobacco control policy in the United States: synthesis of federal, state, and local policy texts. Am J Health Promot. 2017;31(4):302-309.

4. Haddad L, El-Shahawy O, Ghadban R, Barnett TE, Johnson E. Waterpipe smoking and regulation in the United States: a comprehensive review of the literature. Int J Environ Res Public Health. 2015;12(6): 6115-6135.

5. Rahman I, MacNee W. Oxidant/antioxidant imbalance in smokers and chronic obstructive pulmonary disease. Thorax. 1996;51(4):348-350.

6. Chalmers GW, MacLeod KJ, Thomson L, Little SA, McSharry C, Thomson NC. Smoking and airway inflammation in patients with mild asthma. Chest. 2001;120(6):1917-1922.

7. Roth MD, Arora A, Barsky SH, Kleerup EC, Simmons M, Tashkin DP. Airway inflammation in young marijuana and tobacco smokers. Am J Respir Crit Care Med. 1998;157(3 Pt 1):928-937.

8. Willemse BW, Postma DS, Timens W, ten Hacken NH. The impact of smoking cessation on respiratory symptoms, lung function, airway hyperresponsiveness and inflammation. Eur Respir J. 2004;23(3): 464-476.

9. Niewoehner DE, Kleinerman J, Rice DB. Pathologic changes in the peripheral airways of young cigarette smokers. N Engl J Med. 1974; 291(15):755-758.

10. Sunyer J, Anto JM, Kogevinas M, Soriano JB, Tobias A, Munoz A. Smoking and bronchial responsiveness in nonatopic and atopic young adults. Spanish Group of the European Study of Asthma. Thorax. 1997; 52(3):235-238

11. Kabiraj MU, Simonsson BG, Groth S, Bjorklund A, Bulow K, Lindell SE. Bronchial reactivity, smoking, and alpha1-antitrypsin. A populationbased study of middle-aged men. Am Rev Respir Dis. 1982;126(5): 864-869.

12. Stolz D, Anderson SD, Gysin C, Miedinger D, Surber C, Tamm M, Leuppi JD. Airway reactivity to inhaled mannitol in cigarette smokers: a longitudinal study. Respir Med. 2007;101(7):1470-1476.

13. Anderson SD, Brannan J, Spring J, et al. A new method for bronchialprovocation testing in asthmatic subjects using a dry powder of mannitol. Am J Respir Crit Care Med. 1997;156(3 Pt 1):758-765. 
14. Brannan JD, Anderson SD, Perry CP, Freed-Martens R, Lassig AR, Charlton B; Aridol Study Group. The safety and efficacy of inhaled dry powder mannitol as a bronchial provocation test for airway hyperresponsiveness: a phase 3 comparison study with hypertonic $(4.5 \%)$ saline. Respir Res. 2005;6:144.

15. World Medical Association. World Medical Association Declaration of Helsinki. Ethical principles for medical research involving human subjects. Bull World Health Organ. 2001;79(4):373-374.

16. No authors listed. ICH Harmonised Tripartite Guideline. Statistical principles for clinical trials. International Conference on Harmonisation E9 Expert Working Group. Stat Med. 1999;18(15):1905-1942.

17. No authors listed. Standards for the diagnosis and care of patients with chronic obstructive pulmonary disease (COPD) and asthma. This official statement of the American Thoracic Society was adopted by the ATS Board of Directors, November 1986. Am Rev Respir Dis. 1987; 136(1):225-244.

18. Dreborg S. The skin prick test in the diagnosis of atopic allergy. J Am Acad Dermatol. 1989;21(4 Pt 2):820-821.

19. Chaouachi K. Hookah (Shisha, Narghile) Smoking and Environmental Tobacco Smoke (ETS). A critical review of the relevant literature and the public health consequences. Int J Environ Res Public Health. 2009;6(2):798-843.

20. Asfar T, Ward KD, Eissenberg T, Maziak W. Comparison of patterns of use, beliefs, and attitudes related to waterpipe between beginning and established smokers. BMC Public Health. 2005;5:19.

21. Kiter G, Ucan ES, Ceylan E, Kilinc O. Water-pipe smoking and pulmonary functions. Respir Med. 2000;94(9):891-894.

22. Maziak W, Eissenberg T, Ward KD. Patterns of waterpipe use and dependence: implications for intervention development. Pharmacol Biochem Behav. 2005;80(1):173-179.
23. Maziak W, Jawad M, Jawad S, Ward KD, Eissenberg T, Asfar T. Interventions for waterpipe smoking cessation. Cochrane Database Syst Rev. 2015;(7):CD005549.

24. Maziak W, Taleb ZB, Bahelah R, Islam F, Jaber R, Auf R, Salloum RG. The global epidemiology of waterpipe smoking. Tob Control. 2015; 24 Suppl 1:i3-i12.

25. Akl EA, Gunukula SK, Aleem S, Obeid R, Jaoude PA, Honeine R, Irani J. The prevalence of waterpipe tobacco smoking among the general and specific populations: a systematic review. BMC Public Health. 2011;11:244.

26. Raad D, Gaddam S, Schunemann HJ, Irani J, Abou Jaoude P, Honeine R, Akl EA. Effects of water-pipe smoking on lung function: a systematic review and meta-analysis. Chest. 2011;139(4):764-774.

27. Nemmar A, Al Hemeiri A, Al Hammadi N, et al. Early pulmonary events of nose-only water pipe (shisha) smoking exposure in mice. Physiol Rep. 2015;3(3). pii:e12258.

28. Strulovici-Barel Y, Shaykhiev R, Salit J, et al. Pulmonary abnormalities in young, light-use waterpipe (hookah) smokers. Am J Respir Crit Care Med. 2016;194(5):587-595.

29. Primack BA, Hopkins M, Hallett C, et al. US health policy related to hookah tobacco smoking. Am J Public Health. 2012;102(9):e47-e51.

30. Mzayek F, Khader Y, Eissenberg T, Al Ali R, Ward KD, Maziak W. Patterns of water-pipe and cigarette smoking initiation in schoolchildren: Irbid longitudinal smoking study. Nicotine Tob Res. 2012;14(4): 448-454.

31. Maziak W. Rise of waterpipe smoking. BMJ. 2015;350:h1991.

32. Nemmar A, Raza H, Yuvaraju P, et al. Nose-only water-pipe smoking effects on airway resistance, inflammation, and oxidative stress in mice. J Appl Physiol (1985). 2013;15(9):1316-1323.
International Journal of COPD

\section{Publish your work in this journal}

The International Journal of COPD is an international, peer-reviewed journal of therapeutics and pharmacology focusing on concise rapid reporting of clinical studies and reviews in COPD. Special focus is given to the pathophysiological processes underlying the disease, intervention programs, patient focused education, and self management protocols.

\section{Dovepress}

This journal is indexed on PubMed Central, MedLine and CAS. The manuscript management system is completely online and includes a very quick and fair peer-review system, which is all easy to use. Visit http://www.dovepress.com/testimonials.php to read real quotes from published authors. 